\title{
O RENDIMENTO DA PROVA TUBERCULINICA ENTRE COMUNICANTES DE PORTADORES DE TUBERCULOSE PULMONAR EM BELÉM-PA
}

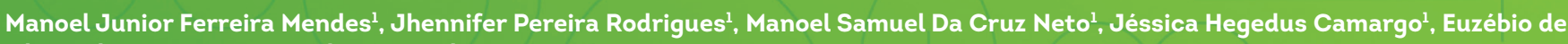
Oliveiral, Antônia Margareth Moita Sá ${ }^{1}$

Objetivo: Determinar o rendimento da Proteína Purificada Derivada (PPD) em comunicantes de tuberculose pulmonar ativa. Metodologia: Trata-se de um estudo descritivo, transversal e de abordagem quantitativa realizado em duas Unidades Básicas de Saúde localizadas em Belém-PA. Participaram da pesquisa 42 comunicantes de ambos os sexos. As informações foram colhidas por meio de um formulário estruturado, com perguntas fechadas e finalizadas com a realização da aplicação do PPD. Resultados: O rendimento do PPD apresentou 22 comunicantes (52,3\%) positivos, 19 comunicantes (45,2\%) negativos e 1 contato (2,3\%) não retornou para a avaliação. Conclusão: A pesquisa demonstra que a maior parte dos comunicantes que realizam a prova tuberculínica podem estar infectados pelo Bacilo de Koch.

Descritores: Tuberculose, Teste Tuberculínico, Tuberculose Latente

\section{THE EFFICIENCY OF TUBERCULIN TEST AMONG THE CONTACTS OF PEOPLE WITH PULMONARY TUBERCULOSIS IN BELÉM-} PA

Objective: To determine the efificiency of Derived Purified Protein (PPD) in active pulmonary TB patients. Methodology: This is a descriptive, cross-sectional study with a quantitative approach carried out in two Basic Health Units located in Belém-PA. Participated in the scientific study 42 contacts of both sexes, which the information was collected through a structured form, with closed questions and finalized with the implementation of the PPD. Results: The PPD efficiency presented 22 positive (52.3\%) communicants, 19 negative (45.2\%) and 1 contact (2.3\%) did not return to the evaluation. Conclusion: Research shows that most contacts who perform the tuberculin test may be infected by Koch bacillus.

Descriptors: Tuberculosis, Tuberculin Test, Latent Tuberculosis.

\section{LA RENDIMIENTO DEL TEST TUBERCULINICO ENTRE COMUNICANTES DE PORTADORES DE TUBERCULOSIS PULMONAR EN BELÉM-PA}

Objetivo: Determinar el rendimiento de la Proteina Purificada Derivada (PPD) en comunicantes de tuberculosis pulmonar activa. Metodología: Se trata de un estudio descriptivo, transversal y de abordaje cuantitativo realizado en dos Unidades Básicas de Salud ubicadas en Belém-PA. Participaron de la encuesta 42 comunicantes de ambos sexos. La información fue recogida a través de un formulario estructurado, con preguntas cerradas y finalizadas con la aplicación del PPD. Resultados: El ingreso del PPD presentó 22 comunicantes (52,3\%) positivos, 19 comunicantes $(45,2 \%)$ negativos y 1 contacto $(2,3 \%)$ no regresó para la evaluación. Conclusión: La investigación demuestra que la mayor parte de los comunicantes que realizan la prueba tuberculínica pueden estar infectados por el Bacilo de Koch Descriptores: Tuberculosis, Prueba de Tuberculina, Tuberculosa Latente 
INTRODUÇÂO

A Tuberculose (TB) é uma doença infectocontagiosa causada pelo Mycobacterium tuberculosis ou Bacilo de Koch (BK). Uma de suas características é o longo período em que pode permanecer em latência, sendo este, um traço peculiar de defesa contra o sistema imunológico do corpo humano. Enquanto outras bactérias se multiplicam a cada duas horas, - BK leva de 12 a 20 horas, apresentando também um longo período de incubação que varia de 4 a 12 semanas. Apesar de o BK atingir vários órgãos do corpo humano, sua forma mais comum de contaminação é a pulmonar ${ }^{1}$.

Tendo como referência os dados de 2015 sobre TB, foi estabelecido o objetivo de erradicar a epidemia até 2030 com o uso da meta $(90,90,90)$ do STOP TB Partnership (Parceria para a paralisação da TB), que visa à identificação de pelo menos $90 \%$ de todas as pessoas com TB no mundo, garantindo o tratamento apropriado e preventivo conforme as indicações. Além disso, pretende alcançar $90 \%$ da população vulnerável, excluídos e os que se encontram em grupos de risco, bem como curar $90 \%$ dos casos diagnosticados ${ }^{2}$.

No Brasil, em 2017, foram notificados 69.569 casos novos de TB. Nesse mesmo ano, o coeficiente de incidência foi igual a 33,5 casos/100 mil hab. No mesmo período, ao realizar um substrato por regiões brasileiras, a Região Norte teve o maior coeficiente de incidência do país com 42,7 casos novos de TB para cada 100 mil hab. Dentre os estados da região, destaca-se o estado do Pará com o maior número de casos novos notificados de TB da região 3.232 (38,8/100 mil hab). Ao passo que na avaliação dos comunicantes de TB pulmonar, a capital paraense, Belém, tem a menor taxa de cobertura de avaliação deste grupo populacional do Brasil, com 8,2\% dos comunicantes examinados. Tais dados mostram que os indicadores do Estado do Pará estão aquém das taxas e metas pactuadas pela administração pública brasileira em convenções internacionais ${ }^{3}$.

Visando a melhoria desses indicadores, em 1999, foi lançado o Plano Nacional do Controle da Tuberculose (PNCT), que envolve o esforço em conjunto das esferas Federal, Estadual e Municipal, com o objetivo de desenvolver ações de planejamento mais efetivo para a TB e seus comunicantes. Uma das metas do PNCT é a identificação de pessoas com a Infecção Latente da Tuberculose (ILTB). O diagnóstico precoce das pessoas com ILTB pode ser obtido através da testagem com o Derivado de Proteína Purificada (PPD) 4 .

A prova tuberculínica (PT) ou teste tuberculínico (TT) padronizada pela Organização Mundial da Saúde constituise na aplicação de 0,1 ml, por via intradérmica do derivado protéico PPD-RT 23 na face anterior do terço médio do antebraço esquerdo, com leitura, realizada após 72 horas da aplicação. O rendimento da PT é caracterizado pelo resultado positivo ou negativo da reação local. APT positiva ou reatora é definida como uma enduração medindo $\geq 5$ milimetros; e uma PT negativa ou não reatora é definida medindo $<5$ milímetros ${ }^{4}$.

No Brasil, o teste tuberculínico é a principal ferramenta de investigação para identificar a ILTB. Apesar de apresentar pouca especificidade em uma população vacinada pela BCG o teste possui uma elevada sensibilidade, tem baixo custo na matéria prima utilizada e na operacionalização de recursos humanos e de materiais para interpretação do exame, tendo em vista ser um método de aplicabilidade simples, tornando-o assim, atraente para a gestão pública ${ }^{5}$

A TB é uma doença curável, mas o sistema de saúde desestruturado, a urbanização não planejada, as práticas e ambientes insalubres são propícios para a disseminação da doença. A forma latente do Micobacterium tuberculosis atua como um complicador, pois enquanto não for identificado, continuará a ser disseminado em meio social (6). A despeito dos custos aos cofres públicos ocasionados pela TB, de acordo com dados do Ministério da Saúde estima-se que a cada caso novo diagnosticado no ano de 2017, e que utilizará o esquema básico para o seu tratamento completo por seis meses dentro da Atenção Primária em Saúde, tem como custo total $\mathrm{R} \$ 118,70$ reais por usuário, ressaltando que este valor refere-se somente ao tratamento farmacológico, excluindo fatores operacionais como ferramentas para elucidação do diagnóstico, controle laboratorial e recursos humanos, que elevam este custo primário de forma substancial, gerando altos valores para a administração pública. Neste sentido, o diagnóstico precoce é um dos grandes desafios para o controle da TB e diminuição dos gastos públicos²

Para tal, também é necessário que as políticas de saúde alcancem os resultados almejados, expressando o compromisso com as diretrizes e princípios que norteiam o Sistema Único de Saúde (SUS) nos cuidados com os usuários de TB. Os cuidados devem ultrapassar os limites do usuário com tuberculose, sendo necessário investigar o meio social dos diagnosticados de TB, identificando os comunicantes para posteriormente reduzir as fontes da doença e interromper o ciclo de infecção, independente das dificuldades locais, materiais e profissionais que podem haver'.

No Brasil, de 30 a 50\% dos diagnósticos de TB são realizados em hospitais, e em média $30 \%$ dos óbitos em TB ocorrem nestes locais, apontando falhas na atenção básica no que se refere à oferta do serviço, à acessibilidade e à aceitabilidade. Uma pesquisa, realizada no município de Vitória no Espírito Santo, mostrou que os usuários que buscam ajuda nas UBS não encontram resolutividade da sintomatologia neste nível de atenção, e com isso, são encaminhados para níveis secundários. Isso evidencia o despreparo dos profissionais em receber o indivíduo que apresenta os sinais 
e sintomas da TB e de identificar em um meio social a busca ativa dos comunicantes ${ }^{7}$.

De acordo com o exposto acima, este trabalho objetivou determinar o rendimento do teste tuberculínico em comunicantes dos portadores de tuberculose pulmonar ativa levantando a seguinte questão de pesquisa: Qual o rendimento da prova tuberculínica entre os comunicantes dos portadores de tuberculose atendidos em duas unidades básicas de saúde de Belém- PA?

\section{OBJETIVOS}

Determinar o rendimento da prova tuberculínica em comunicantes dos portadores de tuberculose pulmonar ativa.

\section{METODOLOGIA}

Trata-se de um estudo descritivo, transversal e de abordagem quantitativa realizado em duas Unidades Básicas de Saúde - UBS, localizadas nos bairros do Guamá e Jurunas, que são regiões historicamente com altos índices de incidência de TB e de elevada densidade demográfica no município de Belém- PA. O estudo contou com uma população de 42 comunicantes, ou seja, comunicantes de usuários com TB pulmonar que estavam cadastrados e em tratamento nas referidas UBS, no período de Fevereiro a Março de 2018. Foram incluidos na pesquisa, comunicantes de pessoas acometidas por TB pulmonar, com idade igual ou acima de dois anos, de ambos os sexos e que não estejam em investigação de TB ativa. Foram excluídos do estudo as gestantes, os portadores de HIV, os usuários cadastrados nas unidades de saúde selecionadas acometidos por TB anteriormente, pessoas em tratamento para doenças imunossupressoras, profissionais de saúde e pessoas que tiverem dificuldade de comunicação.

As variáveis incluíram o sexo, idade, escolaridade, raça/ cor, renda, estado civil, tipo de moradia, naturalidade. Também contou com as características clínicas epidemiológicas dos comunicantes de TB como, o uso de álcool, tabaco e/ou outras drogas, renda, relação de parentesco, a intensidade do convívio com caso índice, grau de parentesco, possui cicatriz vacinal da BCG e as condições de moradia. Além disso, foi avaliado o rendimento da Prova Tuberculínica, considerado positivo quando for igual ou maior que $05 \mathrm{~mm}$.

Após a autorização da realização da pesquisa nas UBS, da aprovação do Comitê de Ética e da assinatura do Termo de Consentimento Livre Esclarecido- TCLE, ou no caso menor de idade foi utilizado o Termo de Assentimento para Menores, assinado pelo responsável. Mediante a isso, foram realizadas as entrevistas dos comunicantes com o auxílio de um formulário estruturado com perguntas fechadas, em seguida, procedeu-se a aplicação do PPD, e por fim, após $72 \mathrm{~h}$, a leitura do teste. A aplicação e interpretação da PT foi realizada somente por um dos autores da pesquisa, com ampla experiência e conhecimento na área.

O projeto foi submetido ao Comitê de Ética em Pesquisa da Escola de Enfermagem Magalhães Barata, da Universidade do Estado do Pará (UEPA) e aprovado segundo o parecer n으 2.290.654 de 21 de setembro de 2017.

\section{RESULTADOS}

A população foi constituída por 42 comunicantes de pessoas com TB. Com relação aos dados socioeconômicos, evidenciou-se que 35 (83, 3\%) se auto declararam como pardos; 27 (64,2\%) tinham menos de 10 anos de estudo; 11 (26,1\%) estavam desempregados; 31 (73,8\%) possuíam renda mensal de 1 a 3 salários mínimos; 26 (61,9\%) moravam em casas de alvenarias, 20 (47,6\%) comunicantes tinham casas de 4 a 5 cômodos, 25 (59,5\%) de 2 a 3 janelas e 21 (50\%) mais de 3 portas (Tabela 1 ).

Tabela 1: Dados Socioeconômicos dos comunicantes de TB ativa. Belém-PA, 2018

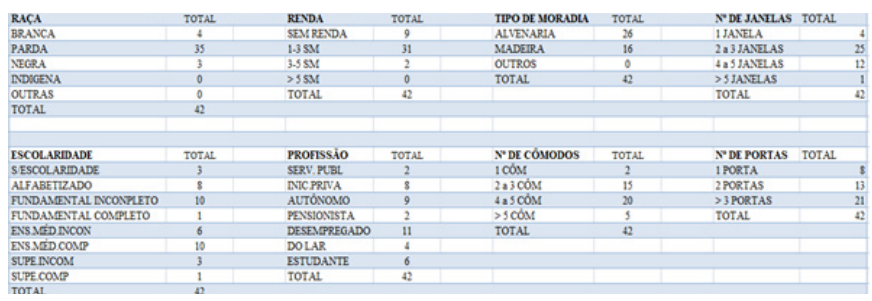

Fonte: Protocolo da Pesquisa

A tabela evidencia que 17 (40,5\%) eram do sexo masculino e 25 (59,5\%) do sexo feminino; com 13 (30,9\%) pessoas na faixa etária de 30 a 49 anos no qual, 13 (30,9\%) eram filhos das pessoas com TB ativa; 30 (71,4\%) não fumavam e 21 (50\%) não ingeriam bebidas alcóolicas (Tabela 2).

Tabela 2: Dados Gerais dos comunicantes de TB ativa. BelémPA, 2018.

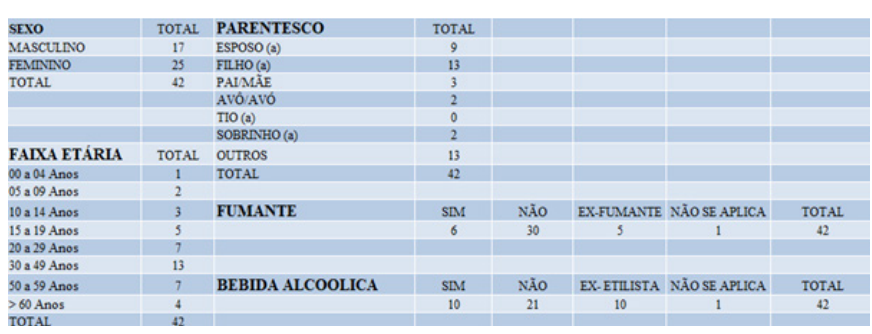

Fonte: Protocolo da Pesquisa.

Em relação aos dados epidemiológicos, 31 (73,8\%) negaram problemas de saúde, 32 (76,1\%) não faziam utilização de medicamentos e 33 (78,5\%) possuíam a cicatriz vacinal da BCG; da magnitude da convivência 36 (85,7\%) comunicantes 
tinham um convívio contínuo com a pessoa com TB ativa, 37 (88\%) moravam na mesma casa, porém 22 (52,3\%) do total da amostra não dormiam no mesmo cômodo e 32 (76,1\%) não dormiam na mesma cama que a pessoa com TB ativa. Por fim, a leitura do PPD revelou 22 comunicantes (52,3\%) positivos, com valores do endurado maior ou igual a $5 \mathrm{~mm}$ e 19 comunicantes (45,2\%) negativos, com enduração menor que $5 \mathrm{~mm}$. Sendo que 1 contato (2,3\%) não retornou para a avaliação (Tabela 3).

Tabela 3: Dados Epidemiológicos dos comunicantes de TB ativa. Belém-PA, 2018.

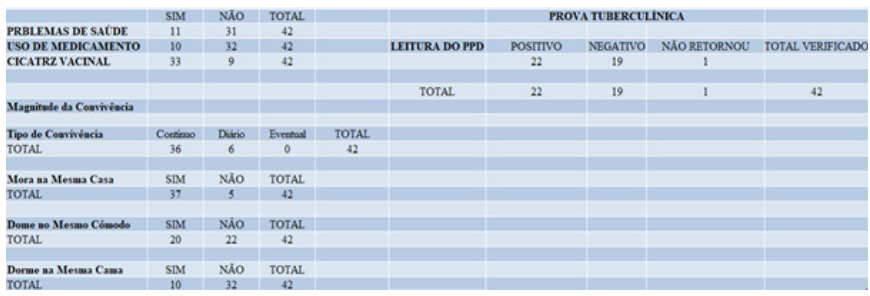

Fonte: Protocolo da Pesquisa

\section{DISCUSSÃO}

Sendo a Região Norte do Brasil no ano de 2017, detentora da maior taxa de incidência de TB, o Estado do Pará contribui de forma relevante para o crescimento desses indicadores ( $42 \%$ dos casos novos notificados), a capital Belém ocupa a quarta maior taxa de incidência de TB do Brasil (84,9/100 mil hab.). É uma doença fortemente influenciada pelas variáveis sociais e demonstra relação direta com indicadores de pobreza e exclusão social. O Índice de Desenvolvimento Humano Municipal (IDHM) de Belém em 2010 foi de 0,746 pontos, na escala de 0 a 1 , ocupando a 628 o posição pelo Atlas do Desenvolvimento Humano no Brasil de 2013. Este baixo IDHM destaca a situação de pobreza existente na cidade e o risco de contrair a TB pela baixa qualidade de vida da população refletindo em suas moradias ${ }^{8}$.

As habitações mais humildes se caracterizam por possuírem poucos cômodos, favorece a aglomeração de pessoas em um mesmo ambiente, além de proporcionar pouca ventilação. O agente causador da TB é um microorganismo que prioriza locais fechados onde há pouca ou nenhuma luminosidade e ventilação. Além disso, quando existem aglomerações em ambientes com tais características, a contaminação pode chegar a $100 \%$. Cuidar dos individuos contaminados deve ser a prioridade, assim como oferecer atenção aos seus comunicantes para o maior controle da tuberculose ${ }^{8}$.

Entre os comunicantes examinados nessa pesquisa (83\%) se autodeclarou de cor parda, contudo, não foram encontrados estudos que relacionam a cor da pele como fator determinante para a presença do Bacilo?.
O estudo identificou a conexão que há entre comunicantes positivos para o PPD (52,3\%) com o baixo nível socioeconômico. 68\% possui menos de 8 anos de estudo e aproximadamente $47 \%$ encontra-se desempregado ou exercendo alguma atividade autônoma Aproximadamente $74 \%$ dos comunicantes desta pesquisa tem renda familiar em torno de 1 a 3 salários mínimos,. Tais resultados, se aproximam dos resultados encontrados em pesquisa realizada no município de Londrina, estado do Paraná, em que se investigou a ILTB em comunicantes de TB pulmonar ${ }^{5}$. Assim como um estudo realizado em um Centro de Saúde no município de Belém com 328 usuários, incluindo os profissionais de saúde, no qual foi avaliado o rendimento da PT, mostrando 59,76\% de rendimento positivo para o PPD com predominância ligada ao baixo nível socioeconômico ${ }^{10}$.

Com isso, a baixa renda afeta o estilo de vida dos comunicantes e a busca da qualidade de vida. Apesar de, cerca de, $62 \%$ das moradias serem de alvenaria, e 47,5\% possuírem residências com quatro a cinco cômodos, 59,5\% dos usuários tinham em seu domicilio apenas duas a três janelas, fator que pode influenciar na disseminação do bacilos, pois o número reduzido de janelas favorecem a pouca ventilação e iluminação na residência, que são fatores determinantes para diminuir a ação do bacilo em meio ambiente ${ }^{11}$. Esses achados corroboram o estudo realizado em uma cidade de médio porte no centro-oeste do Estado de Minas Gerais, que verificou uma maior incidência da ILTB em comunicantes com residências de poucos cômodos e áreas de ventilação ${ }^{12}$

Evidências relacionadas à predominância do sexo feminino, faixa etária predominante e positividade do PPD entre filhos ou cônjuges de pessoas com TB ativa, foram também encontradas em um estudo realizado com 1000 pacientes em um Centro de Saúde na cidade de Belém-PA, em que 610 dos pacientes que realizaram o procedimento foram mulheres e 188 dos pacientes estavam na faixa etária de 31 a 40 anos. Porém o grupo "Pai/Mãe" teve maior frequência de PT positiva ${ }^{13}$

Os Indivíduos que convivem com portadores da TB possuem um risco elevado de infecção e progressão da doença, principalmente, quando esse convivio é intenso e/ ou contínuo, fato demonstrado em estudo realizado com 27 indivíduos da amostra que tiveram contato contínuo com pessoas com TB ativa e, todos apresentaram prova tuberculínica positiva. No estudo em questão, $85,7 \%$ dos comunicantes tinham um convívio contínuo com pessoas que apresentavam TB ativa ${ }^{14}$.

O risco de infecção pelo bacilo da TB é devido ao tempo de exposição com o caso índice, que neste sentido é constante por viverem em uma mesma casa, dormirem no mesmo cômodo, ou em uma mesma cama. Além disso, até haver o 
diagnóstico definitivo da TB, o risco de contaminação de seus familiares próximos é elevado devido à eliminação constante do bacilo?.

Otabagismo atua como um fator de risco para tuberculose latente e tuberculose ativa. As toxinas do cigarro podem provocar desencadeamento dos sintomas da TB pela baixa no sistema imunológico, além de causar a redução do muco ciliar do trato respiratório, deste modo favorecendo o aumentando e a aderência das bactérias e rompendo o epitélio protetor. Estudo realizado em Taiwan chegou a conclusão de que 17\% dos casos de tuberculose naquela população estudada eram atribuídos ao tabagismo. No entanto, aproximadamente $20 \%$ da incidência global da TB está vinculada ao tabagismo ${ }^{15}$. Já, a presente pesquisa evidenciou que $71,4 \%$ das pessoas entrevistadas negam ser fumantes, bem como 50\% negam ingerir bebida alcóolica.

É importante destacar que dos 42 comunicantes avaliados nessa pesquisa, apenas 1 contato (2,3\%) não compareceu a unidade, levando a um saldo positivo em quase $100 \%$ dos pacientes que retornaram após $72 \mathrm{~h}$ para leitura do teste. Este resultado leva ao questionamento sobre a condição de saúde oferecida à comunidade pois, os serviços disponibilizados pela unidade de saúde deveriam suprir as necessidades e demanda da comunidade. Esta falha abrange a dimensão estrutural, relacional e operacional resultando em riscos para as pessoas, como a não identificação dos casos de ILTB e propagação da doença.

\section{LIMITAÇÃO DO ESTUDO}

Neste estudo, ainda que obtidos resultados significativos, considera-se como limitação, o número de participantes, possivelmenterelacionada a não utilização do PPD comorotina na unidade de saúde (Belém examinou 9\% dos comunicantes em 2017) e falta de estratégias de busca destes, o que permite considerar relevantes os resultados encontrados para a realidade estudada e sugere-se realização de estudos com métodos semelhantes em maiores amostras para avaliar a abrangência dos resultados para outras realidades.

\section{CONSIDERAÇÕES FINAIS}

Diante do panorama nacional, a tuberculose ainda configura-se como um grande desafio para a administração pública, especialmente na Região Norte, com alarmante aumento das taxas de incidência de casos novos entre os estados, frente a baixa adesão na avaliação entre os comunicantes de TB pulmonar. Negligenciar este grupo populacional, é distanciar-se do controle desta endemia e fortalecer um banco de infectados.

Essa pesquisa mostra que a maior parte dos comunicantes, ou seja, comunicantes de pessoas com TB ativa podem estar com infecção latente da tuberculose, e que se realizado a prova tuberculínica e descoberto precocemente a infecção, essas pessoas podem ser tratadas evitando a disseminação da doença em meio social. Garantindo assim, a quebra da cadeia de transmissão e consequentemente a diminuição de pessoas com TB ativa.

Para isso, as Unidades Básicas de Saúde devem proporcionar a avaliação dos comunicantes e melhorar o acesso aos indivíduos que necessitam de tratamento para a infecção latente da tuberculose, proporcionando a realização da prova tuberculínica para todos, principalmente para as pessoas de convívio contínuo das pessoas com TB ativa, já que a presente pesquisa mostrou um alto índice de infecção latente nesses comunicantes, bem como, treinando e motivando os profissionais para que reconheçam a importância da realização de estratégias para os grupos de risco, como a educação em saúde. Desta forma, o público alvo obteria maior conhecimento da doença e consequentemente haveria diminuição de novos casos no futuro 
REFERÊNCIAS

1 - Piller RVB. Epidemiologia da Tuberculose. Pulmão RJ. [Internet] 2012:21(1):4-9. [acesso em 23 abr. 2018]. Disponivel em: http://www. sopterj.com.br/wp-content/themes/_sopterj_redesign_2017/_revista/2012/n_01/02.pdf

2 - World Health Organization (WHO) The End TB Strategy. Global strategy and targets for tuberculosis prevention, care and control after 2015. [Internet] [acesso em 23 abr. 2018]. Disponivel em: http://who. int/tb/post2015_TBstrategy.pdf?ua=1

3 - Brasil, Secretaria de Vigilância em Saúde - MS. Boletim Epidemiológico: Indicadores prioritários para o monitoramento do Plano Nacional pelo Fim da Tuberculose como Problema de Saúde Pública no Brasil.[internet] Mar 2018:49(11) 7-10 [acesso em 23 abr. 2018]. Disponivel em: http://portalarquivos2.saude.gov.br/images/pdf/2018/marco/26/2018-009.pdf

4 - Ministério da Saúde (BR), Secretaria de Vigilância em Saúde. Programa Nacional de Controle da Tuberculose. Manual de Recomendações para o Controle da Tuberculose no Brasil. Brasilia: Ministério da saúde. [internet] 2011[acesso em 23 abr. 2018]. Disponivel em: http:// bvsms.saude.gov.br/bvs/publicacoes/manual_recomendacoes_controle_tuberculose_brasil.pdf

5 - Dessunti EM. et al. Infecção latente de tuberculose: adesão ao tratamento e evolução dos casos. Artigo original. Rev. enferm. UERJ, Rio de Janeiro [internet]. $2013 \mathrm{dez}$ [acesso em 23 abr. 2018]; 21(esp. 2):711-7. Disponivel em: http://www.facenf.uerj.br/v2lesp2/v2le2a03.pdf

6 - Alves MV. A tuberculose hoje: a doença que, no passado, vitimou poetas, músicos, cientistas e pintores ainda é problema de saúde pública no século XXI. Rev pré UNIVESP [internet]. Dez. 2016/ Jan. 2017 [acesso em 23 abr. 2018];61. Disponivel em: http://pre.univesp.br/a-tuberculose-hoje\#.WRtEueXyvIU

7 - Loureiro RB. Acesso ao diagnóstico da tuberculose em serviços de saúde do municipio de Vitória, ES, Brasil. Ciênc saúde coletiva [internet]. 2014 [acesso em 23 abr. 2018];19 (4): 1233-1244. Disponivel em: http://www.scielosp.org/pdf/csc/v19n4/1413-8123-csc-19-04-01233. pdf

08 - Costa RR. Tuberculose: perfil epidemiológico em hospital referência no tratamento da doença. Rev Med Minas Gerais. [internet] 2014; [acesso em 23 abr. 2018] 24.(Suppl.5). Disponivel em: http://www. rmmg.org/artigo/detalhes/1623

09 - Brasil. Ministério da Saúde. Secretaria de vigilância em saúde. Departamento de vigilância epidemiológica. Tratamento diretamente observado (TDO) da tuberculose na atenção básica. [internet] 2010 [acesso em 23 abr. 2018]. Disponivel em: http://bvsms.saude.gov.br/ bvs/publicacoes/tratamento_diretamente_observado_tuberculose. pdf
10 - Carvalho JG. Rendimento da prova tuberculinica na investigação da tuberculose latente [Dissertação para titulo de Mestrado] Belém. Universidade Federal do Pará. UFPA [internet]. 2012 [acesso em 23 abr. 2018]. Disponivel em: https://tede.ufam.edu.br/bitstream/ tede/5719/2/Disserta\%C3\%A7\%C3\%A30\%20-\%20Josiane\%20Carvalho.pdf

11 - Barbosa EL, Levino A. Análise da coinfecção TB/HIV como fator de desenvolvimento da tuberculose multidroga resistente: uma revisão sistemática. Rev Pan-Amaz Saude. 2013; [acesso em 23 abr. 2018] 4 (4): 57-66. Disponivel em: http://scielo.iec.gov.br/pdf/rpas/v4n4/v4n4a07. pdf

12- Oliveira CL, Melo AC, Oliveira LRS, Froede EL, Camargo P. Medidas de controle dispensadas a comunicantes $\leq 15$ anos de casos indices com tuberculose pulmonar ativa. J Bras Pneumol. 2015; [acesso em 23 abr. 2018] 4l(5):449-453. Disponivel em: http://www.scielo.br/pdf/ jbpneu/v4ln5/pt_1806-3713-jbpneu-41-05-00449.pdf

13 - Barros PG. Perfil Epidemiológico dos casos de Tuberculose Extrapulmonar em um municipio do estado da Paraiba 2001-2010. Cad. Saúde Colet [internet]. 2014 [acesso em 23 abr. 2018]; 22 (4): 343-50. Disponivel em: http://www.scielo.br/scielo.php?pi$d=S 1414-462 \times 2014000400343 \varepsilon$ script=sci_abstract\&tlng=pt

14 - Figueiredo Jr AM. Prevalência da infecção latente tuberculosa em comunicantes de portadores de tuberculose pulmonar. 73 Folhas. [Dissertação]. Belém-PA: Escola de Enfermagem, Universidade do Estado do Pará; [internet] 2015. [acesso em 23 abr. 2018] Disponivel em: https://paginas.uepa.br/ppgenf/files/DISSERTAO_ADILSON_MENDES.pdf

15- Zelner, J. L. et al. Bacillus calmette-gue' rin and isoniazid preventive therapy protect contacts of patients with tuberculosis. Am J Respir Crit Care Med. 2014. [internet] 189(7):853-9 [acesso em 23 abr. 2018] Disponivel em: https://www.ncbi.nlm.nih.gov/pubmed/24592878

16 - Rabahi MF. Tuberculose e Tabagismo. Pulmão RJ. 2012; [internet] 21 (1): 46-49 [acesso em 23 abr. 2018] Disponivel em: http://www.sopterj.com.br/profissionais/_revista/2012/n_01/1l.pdf

17 - Peruhype RC. Distribuição da tuberculose em Porto Alegre: análise da magnitude e coinfecção tuberculose-HIV. Rev Esc Enferm USP. 2014: [internet] 48 (6): 1035-43. [acesso em 23 abr. 2018] Disponivel em: http://www.scielo.br/pdf/reeusp/v48n6/pt_0080-6234-reeusp-48-06-1035.pdf 